\title{
Histomorphological features of benign soft tissue tumors in a medical college of North India
}

\author{
Megha Bansal ${ }^{1}$, Honey Bhasker Sharma ${ }^{2, *}$, Nikhilesh Kumar ${ }^{3}$ \\ ${ }^{1,2}$ Assistant Professor, ${ }^{3}$ Professor and HOD, Dept. of Pathology, T.S Misra Medical College \& Hospital, Lucknow, Uttar Pradesh,
} India

*Corresponding Author:

Email: honeyshams11@gmail.com

\begin{abstract}
Introduction: Soft tissue tumors are tumors originating from non-epithelial tissues of the body and are seen in extra skeletal location. They do not include glia, reticulo-endothelial system and other supporting tissues of different parenchymal organs. Classification of soft tissue tumors has histogenetic basis, based on the adult tissue to which they bear a resemblance.

Objective: To evaluate the histomorphological features of benign soft tissue tumors in the different age groups and gender as seen in a medical college of North India, giving clue about prevalence of disease morphology in particular region.

Materials and Methods: This study was retrospective and was done in the department of Pathology, T. S. Misra Medical College and Hospital, Lucknow, Uttar Pradesh. All biopsies diagnosed as benign soft tissue tumors in our Pathology department during study period of two years and eight months were reviewed retrospectively in the present study.

Results and Conclusion:

Benign soft tissue tumors in our region have the peak age of incidence in the fourth decade of life. They are slightly more common in males with male: female ratio of 1.6:1. Commonest benign soft tissue tumor is lipomatous tumor. Extremities are the commonest site of these soft tissue tumors.
\end{abstract}

Keywords: Soft tissue, Benign, Lipomatous, Vascular.

\section{Introduction}

As per definition, benign soft tissue tumors are mesenchymal proliferations which occur in extraskeletal non-epithelial tissue of the body excluding the viscera, coverings of brain and lymphoreticular system. ${ }^{1}$ Classification of soft tissue tumors are based according to the adult tissue to which they bear a resemblance e.g. Lipomas and Liposarcomas are tumors that resemble normal fatty tissue to a varying degree and Haemangiomas and Angiosarcomas contain cells that resemble vascular endothelium. ${ }^{2}$

Benign soft tissue tumors have little propensity for local invasion. They also have less recurrence after conservative treatment. Whereas soft tissue tumors which are malignant or sarcomas are locally aggressive, invasive and cause destructive growth with high incidence of recurrence or distant metastasis. ${ }^{3}$

Benign soft tissue tumors are more common than sarcomas (more than 100 times)and most are located in superficial (dermal or subcutaneous) soft tissue tumors. ${ }^{4}$ Commonest location of these soft tissue tumors are extremities, trunk, abdominal cavity and head and neck region. ${ }^{6}$

Most soft tissue tumors have no antecedent cause, rarely radiation exposure, burn injury or toxin exposure is implicated. ${ }^{5}$ Usage of specialstains, immunohistochemistry and molecular or cytogenetic methods are helpful in increasing specificity of diagnosis made by conventional light microscopy. ${ }^{9}$

By this study, histomorphological features of benign soft tissue tumors as seen in a medical college of North India were thoroughly evaluated. Further aim of the study was to determine age distribution, gender distribution and site distribution of these soft tissue tumors in a particular region of North India.

\section{Materials and Methods}

The present study was conducted in the department of Pathology, T.S.M Medical College and Hospital, Amausi, Lucknow, Uttar Pradesh, India. This study which was first of its kind in this semi-rural area was performed in the recently established medical college. The study was performed retrospectively and cases diagnosed as benign soft tissue tumors on histopathological examination during a period of two years and eight months. (Dec 2015 to July 2018) were reviewed.

In our study, 100 benign soft tissue tumor cases are studied. Detailed clinical history, gross findings, radiological findings, other relevant data and required information were taken from record section. We reviewed slides of these tumors. In few cases, new slides were made from specimen blocks and they were reviewed accordingly.

\section{Results}

In the present study, the slides of 100 surgically removed biopsies which were diagnosed as benign soft tissues tumors on histopathology were retrospectively reviewed and accordingly following results were inferred.

According to our study, most patients of these benign soft tissue tumors were in the age group of 21- 
50 years with maximum percentage in 31-40 years age group (Table 1).

Table 1: Age group

\begin{tabular}{|l|c|}
\hline Age (years) & Percentage $\mathbf{( \% )}$ \\
\hline $0-10$ & 03 \\
\hline $11-20$ & 07 \\
\hline $21-30$ & 21 \\
\hline $31-40$ & 25 \\
\hline $41-50$ & 24 \\
\hline $51-60$ & 12 \\
\hline $61-70$ & 05 \\
\hline $71-80$ & 03 \\
\hline
\end{tabular}

Our study showed that benign soft tissue tumors in our region showed a male preponderance with $62 \%$ males and $38 \%$ female patients. Male to female ratio is of 1.6:1

Present study also showed that most common location of these benign soft tissue tumors in our region is extremities $(37 \%)$ followed by shoulder and back $(30 \%)$ (Table 2).

Table 2: Location of tumors

\begin{tabular}{|l|c|}
\hline \multicolumn{1}{|c|}{ Site distribution } & Percentage (\%) \\
\hline Extremity & 37 \\
\hline Head and neck & 22 \\
\hline Shoulder and back & 30 \\
\hline Trunk and abdomen & 09 \\
\hline Others & 02 \\
\hline
\end{tabular}

Present study also demonstrated that in benign soft tissue tumors, adipose tissue tumors were commonest tumor group (59\%) in our region, followed by vascular tumors $(13 \%)$ and then by nerve sheath tumors $(12 \%)$.(Table 3$)$.

Table 3: Distribution of benign tumors

\begin{tabular}{|l|c|}
\hline \multicolumn{1}{|c|}{ Benign Tumors } & $\begin{array}{c}\text { Percentage } \\
(\%)\end{array}$ \\
\hline Adipocytic tumors & 48 \\
\hline Lipoma & 07 \\
\hline Fibrolipoma & 01 \\
\hline Spindle cell lipoma & 02 \\
\hline Pedunculated lipoma & 01 \\
\hline Angiolipoma & \\
\hline Vascular tumors & 08 \\
\hline Capillary haemangioma & 03 \\
\hline Arterio-venous haemangioma & 01 \\
\hline Cavernous haemangioma & 01 \\
\hline Spindle cell haemangioma & \\
\hline Nerve sheath tumors & 07 \\
\hline Schwannoma & 05 \\
\hline Neurofibroma & \\
\hline Fibro-histiocytic tumors & 04 \\
\hline Giant cell tumor of tendon sheath & \\
\hline
\end{tabular}

\begin{tabular}{|l|c|}
\hline Benign fibrous histiocytoma & 01 \\
\hline $\begin{array}{l}\text { Fibroblastic / myofibroblastic } \\
\text { tumors }\end{array}$ & \\
\hline Fibroma of tendon sheath & 03 \\
\hline Angiofibroma & 01 \\
\hline Ganglion & 05 \\
\hline $\begin{array}{l}\text { Gastrointestinal stromal } \\
\text { tumors }\end{array}$ & 02 \\
\hline
\end{tabular}

The commonest benign tumor was lipoma as observed on histopathology, which constituted $48 \%$. The adipocytic tumors also showed variants like angiolipoma, fibrolipoma, spindle cell lipoma [Fig. 1 \& 2] and pedunculated lipoma. The angiolipoma variant showed mature adipocytes intermingled with inter anastomosing branching capillaries [Fig1]. Whereas, spindle cell lipoma variant demonstrated a mixture of mature adipocytes and bland spindle cells with fibrous background and thick collagen bundles [Fig. 2].

In our study, vascular tumors $(13 \%)$ were the second most common benign tumors. In vascular tumors, $8 \%$ were capillary haemangiomas. The other vascular tumors constituted cavernous haemangioma, arterio-venous haemangiomas and spindle cell haemangioma [Fig. 4]. The cavernous haemangioma was composed of dilated, vascular spaces separated by connective tissue stroma. Flattened endothelial cells lined the vascular spaces, which were filled with blood [Fig. 3].The spindle cell haemangioma showed bland spindle cell proliferations between vascular lumina [Fig. 4].

The third most commonly diagnosed entity were the nerve sheath tumors comprising of $7 \%$ schwannomas [Fig 5] and 5\% neurofibromas. One case was diagnosed as plexiform neurofibroma [Fig. 6]. Schwannomas diagnosed in our study were biphasic with compact hypercellular Antoni A areas and myxoid hypocellular Antoni B areas. Cellular areas showed nuclear palisading around fibrillary process (Verocay bodies).Antoni B areas showed prominent large, irregularly spaced vessels [Fig. 5]. The plexiform neurofibroma demonstrated enlargement of subcutaneous nerves in a cylindrical fashion. Beside nerve fascicles, a cellular matrix comprising of Schwann cells, fibroblasts, collagen and mucin wasseen. [Fig. 6].

The fibrohistiocytic tumors were Benign fibrous histiocytoma and Giant Cell Tumor of tendon sheath. Five cases of ganglion were seen. Two cases of benign Gastrointestinal stromal tumor were also diagnosed.

\section{Discussion}

Soft tissue tumors represent the non-epithelial tissue of body of extra skeletal origin and do not include glia, reticulo-endothelial system and supportive connective tissue of parenchymal organs. In soft tissue tumor diagnosis, open biopsy is more accurate than core needle biopsy and fine needle aspiration. ${ }^{15}$ Soft 
tissue tumors can be seen in any age group but there is a relation between patients age, gender, location and type of tissue. ${ }^{17}$

In our study, slides of 100 cases of benign soft tissue tumors diagnosed in the histopathology division of our department of Pathology were retrospectively reviewed. When we studied the age group, we found that most of the cases in our study were in 31-40 years age group. This is consistent with results obtained by Navya Narayan et al. ${ }^{9}$

Present study of the benign soft tissue tumors, showed a male preponderance of 1.6:1. There were 62 male patients and 38 female patients. Similar studies by Jain et al and Prabhakar et al reported Male to female ratio of 1.2:1, Jobanputra et al reported sex ratio of 1.4:1, Narayan et al showed ratio of 1.7:1 and Dowerah et al showed ratio of $1.3: 1.1,10,2,9,12$ Whereas study by Myre-Jensen demonstrated that benign soft tissue tumors had slightly more incidence in female population. $^{11}$

Most common location of benign soft tissue tumors in our study was extremities $(37 \%)$ followed by shoulder and back (30\%). This is similar to study by Jain et al, Narayan et al, Batra et al, Goyal et al in which extremities was the commonest location of benign soft tissue tumors. However, these studies showed that head and neck was second most common location. ${ }^{1,9,13,7}$

Our study revealed adipocytic tumors as most common benign tumours and included Lipoma, Fibrolipoma, Spindle cell lipoma, Pedunculated lipoma and Angiolipoma. This was followed by vascular tumors. This was comparable to studies by Jain et al, Goyal et al, Anitha et al and Narayan et al, in which the most common benign tumours were lipomas followed by hemangiomas. ${ }^{1,7,8,9}$ Whereas, study by Dowerah and Makino reported the most common tumor as haemangioma followed by lipomas. ${ }^{12,16}$

According to Umarani et al and Batra et al, the commonest soft tissue tumors were adipocytic tumors and nerve sheath tumors were second most common type. ${ }^{14,13}$

Two cases of benign Gastrointestinal Stromal Tumour were diagnosed (Fig. 7). These showed CD117 positivity (Fig. 8).

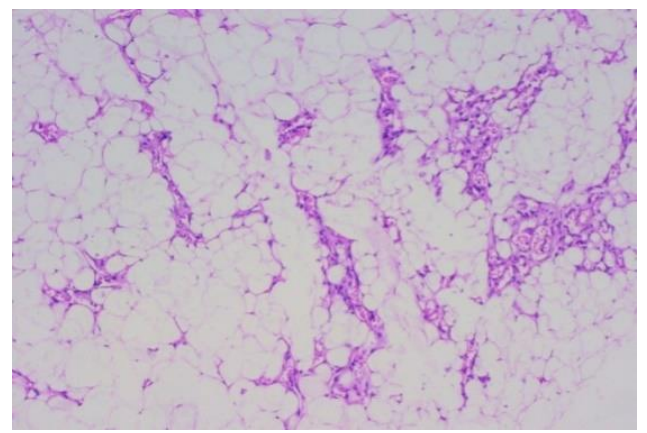

Fig. 1: Angiolipoma [10x,H\&E]

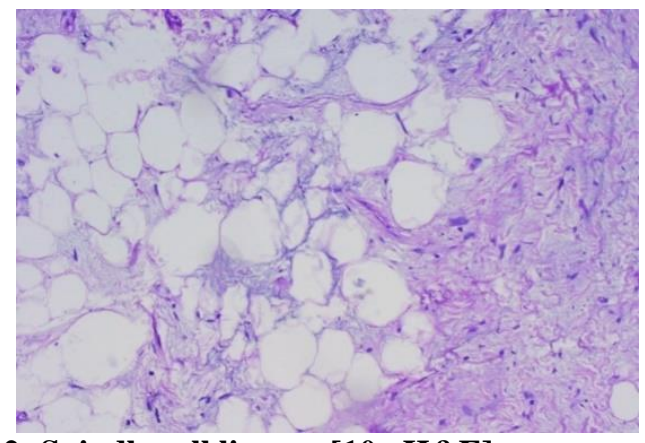

Fig. 2: Spindle cell lipoma $[10 x, H \& E]$

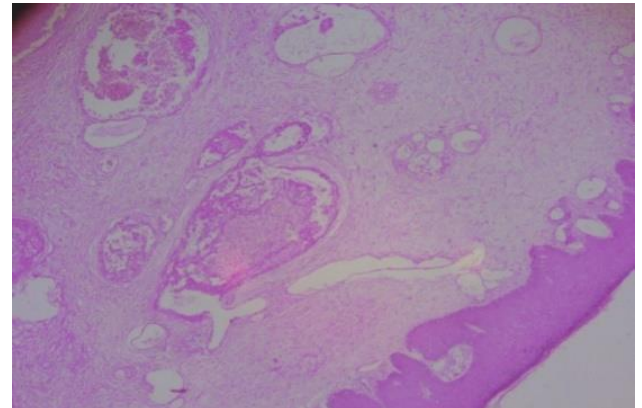

Fig. 3: Cavernous haemangioma [5x,H\&E]

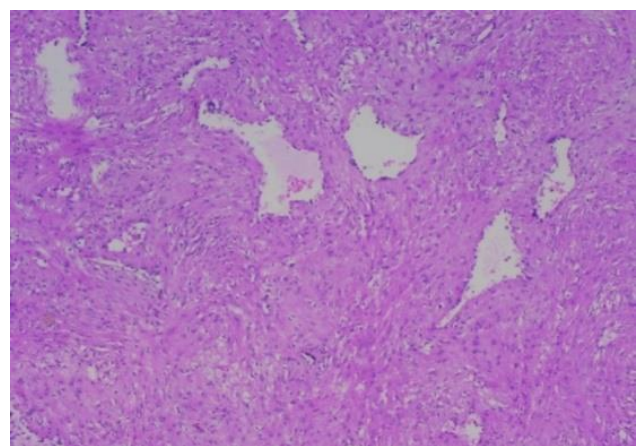

Fig. 4: Spindle cell haemangioma $[10 x, H \& E]$

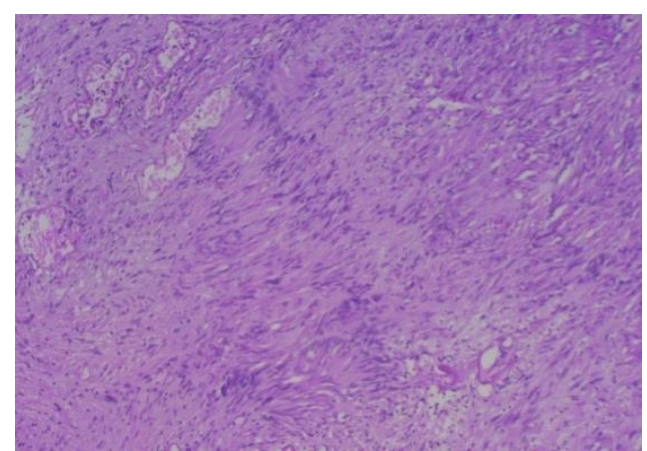

Fig. 5: Schwannoma [10x,H\&E] 


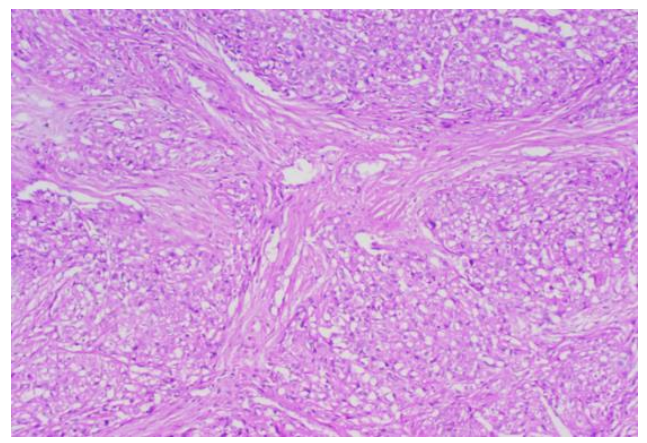

Fig. 6: Plexiform Neurofibroma $[10 x, H \& E]$

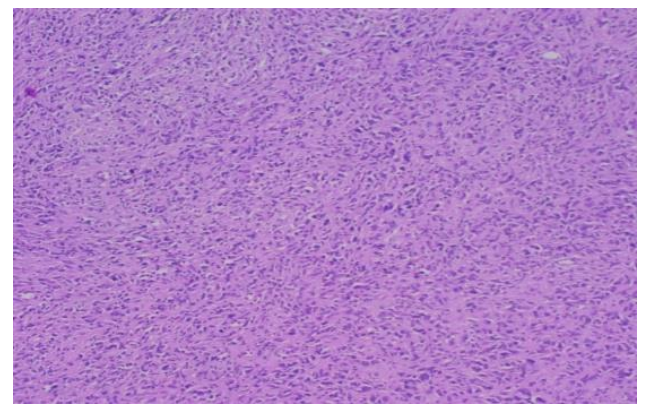

Fig. 7: Gastrointestinal Stromal Tumor [40x, H\&E]

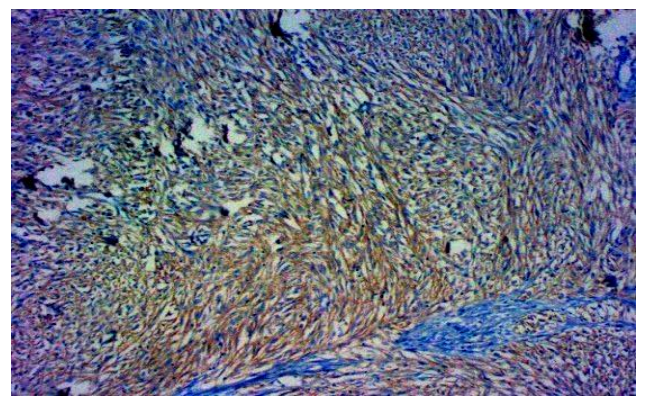

Fig. 8: Gastrointestinal stromal tumor (40x, CD 117 positive)

\section{Conclusion}

Gold standard for diagnosis of soft tissue tumors is clinico-morphological review with proper and careful gross examination and microscopic examination of haematoxylin and eosin (H\&E) stained sections.

Benign soft tissue tumors in our region of North India are more common in the fourth decade of life and show slight male preponderance. Extremities are the commonest site of these soft tissue tumors. Lipomas, followed by hemangiomas are the most common amongst the benign tumors in our area of North India.

Funding: No funding sources.

Conflict of interest: None declared.

\section{References}

1. Jain P, Shrivastava A, Malik R. Clinicomorphological Assessment of Soft Tissue Tumors. Sch J App Med Sci 2014;2(2D):886-90.

2. Jobanputra GP, Parikh UR, Goswami HM. Histopathology study of soft tissue tumors (A study of 140 cases) in tertiary care center. Int J Cur Res Rev 2016;8(20):43-8.

3. Weiss SW, Goldblum JR. General considerations. Enzinger \& Weiss Soft Tissue Tumors, $4^{\text {th }}$ edition: Mosby publications 2001;20011-19.

4. Fletcher CDM, Unni K, Mertens K eds. WHO Classification of Tumors. Pathology and Genetics. Tumors of soft tissue and bone. Lyon: IARC Press;2002.

5. Rosenberg AE. Bones, Joints and Soft Tissue Tumors. Chapter 26 In: Robbins and Cotran Pathologic Basis of Disease by Kumar Abbas and Fausto, $9^{\text {th }}$ edition, Saunders: Elsevier,2004;1273-324.

6. Hassawi BA, SulimanAY, Hasan IS; Soft Tissue TumorsHistopathological study of 93 cases. Ann Coll Med Mosul 2010;36(1\&2):92-8.

7. Goyal S, Bala J, Goyal R, Chowdhary K, Narula A. Histopathological spectrum of soft tissue tumor in tertiary care center. Int J Clin Exp Physiol 2015;2:142-43.

8. Anitha S, Kanya Kumari M; Spectrum of soft tissue tumors based on histomorphology. Medpulse. Int J Pathol 2017;3(1):36-9.

9. Narayanan N, Sapna M, Sumangala B. Spectrum of soft Tissue Tumors in a Tertiary Care Centre. Natl J Med Dent Res 2016;4(2):83-8.

10. Patro P, Pereira E, Desai A, Mahore K, Dhar R, Jain T. Panorma of Soft Tissue Tumors at Tertiary Care Center in Navi Mumbai. Int J Res Rev 2017;4(7):24-9

11. Myhre-Jensen O. A consecutive 7-year series of 1331 benign soft tissue tumors. Clinicopathologic data. Comparison with sarcomas. Acta Orthop Scand 1981;52(3):287-93.

12. Dowerah S, Thapa G, Saikia P. Spectrum of soft tissue tumors at a tertiary care centre in North-East India. Indian J Basic Applied Med Res 2016;5(4):303-6.

13. Batra P, Gupta DO, Batra R, Kothari R, Bokariya P. Pattern of soft tissue tumors in a rural population of Central India. Innovative J Med Health Sci 2013;3:12426.

14. Umarani M.K, Prima Shuchita Lakra, Bharathi M; Histopathological spectrum of Soft Tissue Tumors in a teaching Hospital. IOSR J Dent Med Sci 2015;14(4):7480.

15. Kasraeian S, Allison D, Alhmann ER, Fedenko AN, Menendez LR. A comparison of Fine- needle aspiration, Core Biopsy and Surgical Biopsy in the Diagnosis of Extremity Soft Tissue Masses. Clin Orthop Relat Res 2010;468:2992-3002.

16. Makino Y. A Clinicopathological sudy on soft tissue tumors of the head and neck. Acta Pathol Jpn 1979;29(3):389-408.

17. Kransdorf MJ.Benign Soft Tissue Tumors in a large Referral Population: Distribution of Specific Diagnoses by Age, Sex and Location. AJR 1995;164:395-402.

How to cite this article: Bansal M., Sharma H., Kumar N. Histomorphological features of benign soft tissue tumors in a medical college of North India. J Diagn Pathol Oncol 2018;3(4):340-43. 